\title{
MODELAGEM DO FLUXO DE INFORMAÇÕES DO PROCESSO DE APOSENTADORIA: aplicação em uma universidade pública federal brasileira
}

\author{
MODELING THE INFORMATION FLOW OF A RETIREMENT PROCESS: \\ application in a Brazilian Federal Public University
}

\author{
Luciana Pessoa Guedes Lira' \\ Eli Lopes da Silva \\ Nadi Helena Presser ${ }^{3}$
}

\begin{abstract}
RESUMO
Propõe uma matriz de governança do fluxo de informações do processo de aposentadoria dos professores de uma universidade pública federal. Metodologicamente é uma pesquisa de natureza aplicada, a partir da intencionalidade explícita de resolver problemas práticos imediatos; tem finalidade descritiva, pela enumeração das atividades que compõem o processo de aposentadoria e, principalmente, exposição das informações necessárias para que tais atividades possam ser concretizadas; de abordagem qualitativa, a coleta de dados foi obtida em documentos e entrevistas. A pesquisa valeu-se de discussões teóricas, da análise da legislação federal e de ferramentas de gestão, para identificar, descrever, documentar e construir a matriz de governança. Como resultados, foram apresentadas todas as atividades do processo de aposentadoria e o fluxo de informacões, com suas entradas, saídas, restrições, orientações e retornos. Esses resultados permitiram conhecer a lista de atividades, suas relações e a cronometria (sequenciamento), bem como 0 vasto fluxo de informações necessárias para que todas as etapas do processo de aposentadoria sejam cumpridas. De forma conclusiva, esta pesquisa consegue cobrir a lacuna existente de mostrar efetivamente o fluxo de informações do processo de aposentadoria, pois é lugar comum priorizar as atividades sem considerar a relevância das informações no processo. A matriz de governança, objeto deste trabalho, responde à pergunta: 0 que essas ferramentas conseguem mostrar da informaç̧ão necessária para conduzir os processos? Esta é uma grande contribuição que esta pesquisa deixa.
\end{abstract}

Palavras-chave: Fluxo de informações. Aposentadoria dos professores. Matriz de governança. Design Structure Matrix (DSM). Integration Definition for Function Modeling (IDEF).

\begin{abstract}
This paper proposes a governance matrix for the information flow of the retirement process of professors at a Federal Public University. Methodologically, it is a research of applied nature, since it is aimed at solving an immediate practical problem. Furthermore, it is a descriptive research, listing activities making up the retirement process and, mainly, exposing the necessary information for such activities to be carried out. The research uses a qualitative approach; data collection was carried out by consulting documents and by conducting interviews. The research used theoretical discussions, analysis of federal legislation and management tools to identify, describe, document and build the governance matrix. The results present all the activities making up the retirement process, as well as its information flow, with their respective inputs, outputs, restrictions, guidelines and feedback. This allowed to define the activities list, their relationships and timing (sequencing), as well as the vast information flow being necessary to fulfill all stages of the retirement process. This research manages to fill the existing gap related to the information flow of the retirement process in Federal Public Universities, allowing to prioritize specific activities. The main contribution of this paper is to show how a governance matrix can be used to identify the information needed to conduct processes.
\end{abstract}

Keywords: Information flow. Retirement of professors. Governance matrix. Design Structure Matrix (DSM). Integration Definition for Function Modeling (IDEF).

Artigo submetido em 23/06/2020 e aceito para publicação em 07/07/2020

1 Mestre em Gestão Pública para o Desenvolvimento do Nordeste Universidade Federal de Pernambuco, Brasil. ORCID https://orcid. org/0000-0002-1298-8023. E-mail: luciana_pgs@hotmail.com

2 Professor da Pós-Graduação Faculdade de Tecnologia Senac Florianópolis, Brasil. ORCID https://orcid.org/0000-0002-2950-8938. E-mail: elilsilva@globo.com

3 Professora no Mestrado Profissional em Desenvolvimento e Gestão Pública Universidade Federal de Pernambuco, Brasil. ORCID https://orcid.org/0000-0002-1585-117X. E-mail: nadihelena@uol.com.br 


\section{INTRODUÇÃO}

Tão importante quanto as pessoas dentro de uma organização são as informações por ela utilizadas e como essas informações são processadas. A informação se tornou estratégica para as instituições na contemporaneidade e, como afirma Al-Hakim (2008), o mapeamento dos fluxos de informações é um aspecto importante que deve ser considerado para que haja qualidade nas atividades a serem executadas.

Assim, mais que definir quais atividades devem ser executadas em cada processo dentro as organizações, deve-se levar em conta a quantidade e, principalmente, a qualidade das informações que perpassam por esses fluxos, pois elas é que podem atrasar, adiantar, mitigar ou impedir que os as atividades requeridas no processo sejam executadas. Nesse sentido, utilizar ferramentas de gestão que permitam não apenas mapear atividades, mas esses fluxos informacionais, é chave para que os processos ocorram de maneira mais eficiente.

Para tal, a perspectiva adotada por Al-Hakim (2008), na qual o fluxo de informações entre as várias atividades de um processo como determinantes ou variantes que afetam as atividades subsequentes ou mesmo aquelas que têm informações que precisem retroceder para atividades anteriores, mostra que a qualidade desses fluxos determina a forma mais eficiente de execução do trabalho ou atividade.

Tradicionalmente, o foco de ferramentas de mapeamento de processos, dentre elas os fluxogramas, está centrado no sequenciamento de atividades, como afirma Eppinger (2001). Por outro lado, a perspectiva de fluxos da informação direciona pesquisadores e profissionais a responder quais informações são necessárias de outras atividades antes de completar a existente. Assim, segundo Lillrank (2003), uma questão central é a qualidade das informações que regulam ou restringem o sequenciamento dos atos.

As ferramentas de mapeamento costumam ser utilizadas para identificar entradas e saídas. Mas, para Al-Hakim (2008), três elementos devem ser adicionados, quando se quer dar atenção não apenas aos processos, mas ao fluxo de informações: orientação, restrição e feedback. Esses elementos adicionais formam a "informação de governança", que, de acordo com 0 autor, gerencia, regula e controla a implementação das atividades. A identificação de elementos de informações de governança e suas interdependências é o primeiro passo para melhorar a variação do processo em termos de redução de atrasos e interrupções (Al-HAKIM, 2008).

Dado este contexto, o presente artigo tem como objetivo propor uma matriz de governança do fluxo de informações do processo de aposentadoria dos professores de uma universidade pública federal. 
A orientação dos passos a serem seguidos para requerer a aposentadoria, portanto, pode incluir um conjunto de alternativas, dependendo de cada caso. Logo, o entendimento de ações anteriores a cada passo pode influenciar ou restringir a seleção de uma alternativa ou ajustar a orientação do passo atual. Por exemplo, uma aposentadoria voluntária pode afetar a seleção de alternativas específicas para um procedimento subsequente.

0 fluxo de informações é a base, o que fundamenta o processo de aposentaria. Para um professor da universidade pública federal solicitar a aposentadoria, deve ser providenciada uma série de documentos para completar todo o processo. Certamente o que demanda mais recursos é a identificação correta das necessidades de informações entre as várias atividades do processo de aposentadoria. Diante disso, surge então a seguinte pergunta de pesquisa, que deu origem ao objetivo geral apresentado para este artigo: Como melhorar a troca de informações na execução do processo de aposentadoria dos professores de uma universidade pública federal?

Para responder a esta pergunta e atender ao objetivo geral proposto, optou-se por pesquisar a aposentadoria voluntária, por ser a mais recorrente na universidade que foi objeto deste trabalho.

Os objetivos específicos correspondem ao detalhamento do objetivo geral e foram elencados como se segue: mapear o fluxo de informações; identificar os elementos da informação de governança do processo de aposentaria voluntária dos professores; mostrar as interdependências dos elementos da informação de governança do processo.

Em 2019, 0 Congresso Nacional Brasileiro recebeu a nova proposta de Emenda à Constituição da Nova Previdência (PEC 6/2019), a chamada Reforma da Previdência, que modifica o sistema de previdência social, estabelece regras de transição e disposições transitórias, e dá outras providências (BRASIL, 2019). A mudança na lei de aposentadoria está impactando diretamente no fluxo das atividades das universidades, tendo em vista que muitos docentes estão antecipando sua aposentadoria, afetando em aulas, concursos e nomeação de novas vagas. Neiva (2020, mostra, em seu estudo, que de todas as variáveis estudadas a EC nº 103/2019 foi a que trouxe maior impacto nos pedidos de aposentadoria, pois, como a autora informa, a partir do início da tramitação desta EC até a sua implementação houve 70 novos pedidos de aposentadoria voluntária. Quanto mais claro e definido estiver o fluxo de informações para os professores, tanto maior será a contribuição social desta pesquisa.

\section{AS FERRAMENTAS PARA MAPEAMENTO}

Nesta seção são debatidas as ferramentas de mapeamento atividades, aqui utilizadas também para mapear conjuntamente as informações e, principalmente, quais as características das informações 
necessárias para que o fluxo dê informações com qualidade e quantidade suficientes para que as atividades do processo de aposentadoria sejam executadas.

\subsection{A técnica Design Structure Matrix}

Existem inúmeras ferramentas de gestão que permitem fazer o mapeamento de atividades e, com elas, o fluxo de informações que tramitam entre as atividades de cada processo mapeado. Uma das técnicas é a Design Structure Matrix (DSM), em português, Matriz de Estrutura do Projeto.

Para Eppinger (2001), a construção de uma DSM por quem está analisando o fluxo exige que se vá para as bases, ou seja, as equipes que realmente executam as atividades, para identificar nas atividades quais informações elas necessitam de outras equipes para realizarem seus trabalhos. É essencial concentrar-se na entrada, pois, para quem almeja a informação, esta identificação é tão importante quanto a execução de sua atividade. Eppinger (2001) alerta que nem sempre é adequado apostar somente no que os gestores de uma organização dizem, porque eles geralmente não são as pessoas que realizam 0 trabalho e, por isso, podem ter interesse em justificar processos existentes ou desatualizados.

A técnica, segundo Eppinger (2001), consiste em levantar a ordem cronológica da execução das atividades e em seguida organizá-las em formato de matriz, pois cada linha na matriz correspondente a uma atividade, onde devem ser marcadas as outras atividades que fornecem as informações necessárias.

Como exemplo, apresentamos a matriz DSM Figura 1. A leitura ao longo da linha B, por exemplo, informa que essa atividade precisa de informações das atividades A G e J. Por outro lado, ela fornece informações para as atividades E, H e J. 0 mesmo se dá com as demais.

Figura 1 - DSM simplificado

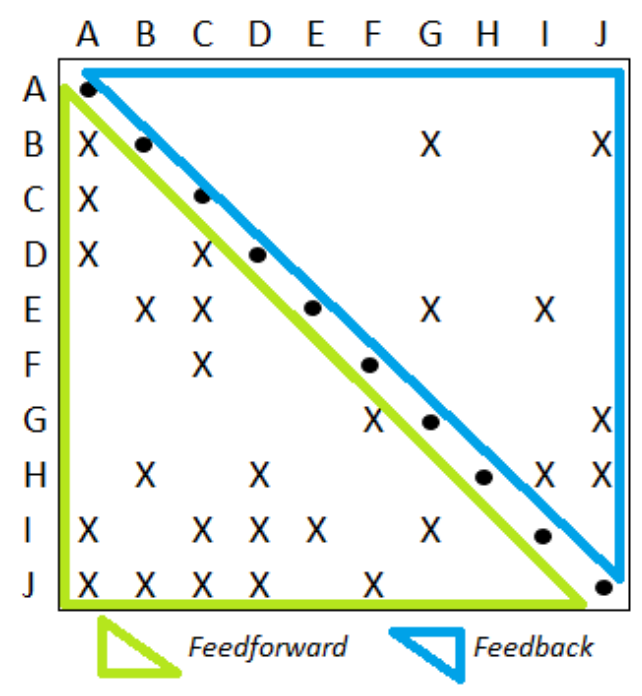

Fonte: Eppinger (2001) 
A matriz revela quais trocas de informações envolvem iteração (repetição) de design e quais não. Na Figura 1, todas as marcações com "X" abaixo da diagonal denotam trocas de informações de feedforward (usando seus resultados ou efeitos antecipados, esperados, previstos), nas quais informações de atividades anteriores estão disponíveis para atividades posteriores. Por outro lado, as marcações com "X" na metade superior denotam um feedback (usando seus resultados ou efeitos) em que informações de uma atividade subsequente podem forçar uma reformulação de uma atividade anterior, explica Eppinger (2001). Essas são as atividades acopladas.

Na DSM são desenhadas caixas em torno das atividades quea organização executa simultaneamente, isto é, de forma paralela e interdependente. Essas são as iterações ${ }^{4}$ planejadas da organização, as atividades que a mesma reconhece como repetidas e, portanto, organiza de modo a facilitar e acelerar 0 fluxo de informações entre elas, como mostra Eppinger (2001). Se todas as marcações "X" acima da diagonal forem capturadas nas caixas, significa que a organização planejou essas iterações (repetições) e organizou seu processo para acomodá-las da maneira mais eficiente possível, afirma Eppinger (2001).

A Figura 2 mostra que as atividades de "E" até "I" são realizadas simultaneamente. No entanto, a organização não conseguiu se preparar para um número razoável de possíveis iterações: ainda há quatro marcas de feedback (agora representadas pela letra "0") acima da diagonal e fora das atividades da caixa. Estas são iterações não planejadas.

Figura 2 - Exemplo de atividades não planejadas

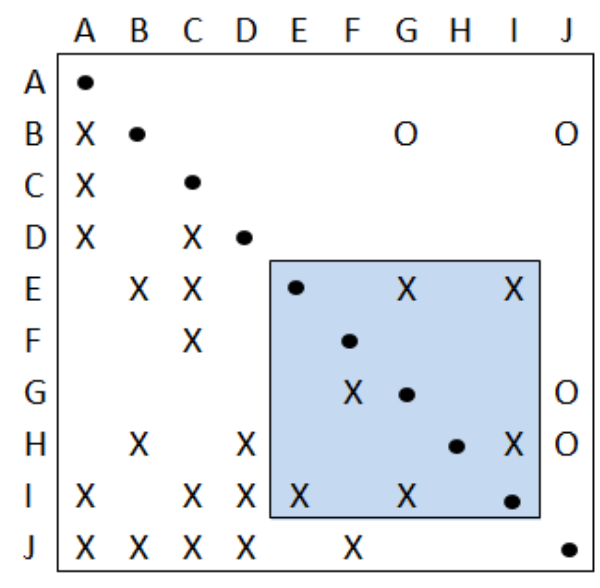
X fluxo de informação
- repetições planejadas
$\mathrm{O}$ repetições não planejadas

Fonte: Eppinger (2001)

4 Ato de iterar; repetição. 
Eppinger (2001) examina quatro maneiras de melhorar os fluxos de informações de uma organização, apresentadas a seguir.

A reorganização da sequência das atividades é uma das maneiras de otimizar os fluxos de informações. 0 primeiro passo na simplificação de um processo de desenvolvimento de produto é determinar se uma sequência diferente de atividades reduzirá o número de marcas de feedback. Isso envolve reorganizar as linhas da DSM, um processo que os executivos da Boeing chamam de "eliminar o retrabalho fora da sequência" (EPPINGER, 2001). 0 objetivo é mover o maior número possível de $X$ acima da diagonal para baixo (Figura 3).

Figura 3 - Otimizar fluxos de informações

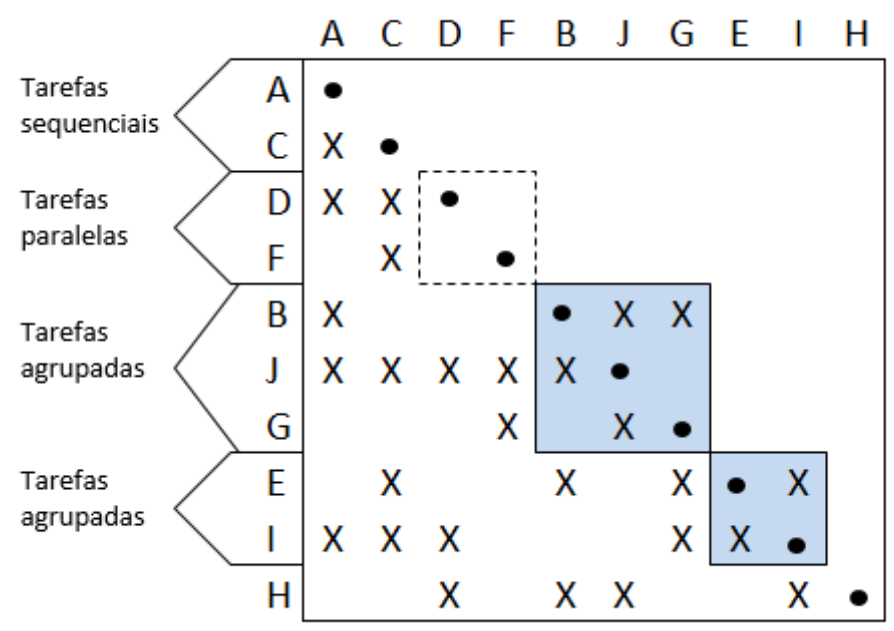

Fonte: Eppinger (2001, p. 10).

Inicia-se identificando candidatos para as atividades mais antigas e mais recentes. Idealmente, a primeira atividade não exigiria nenhuma entrada, indicando que nunca precisaria ser retrabalhada. Por exemplo: referindo-se às duas DSMs das Figuras 1 e 2, a atividade A, portanto, permanece em primeiro lugar. $A$ atividade $C$ vem a seguir porque precisa de informações apenas de $A$; estas são atividades sequenciais.

\subsection{A técnica IDEFO}

0 padrão para modelagem funcional de processos denominado Integration Definition for Function Modeling (IDEF) - Definição Integrada para Modelação de Função - corresponde a um conjunto 
de métodos utilizados para a modelagem estruturada e hierárquica das atividades que compõem um determinado processo, bem como para a identificação das interdependências entre os elementos da atividade (COLQUHOUN, 1993 apud D’ÁVILA, 2006). De acordo com D’Ávila (2006), estão disponíveis dezesseis métodos IDEF, os quais oferecem alto grau de visibilidade aos processos de negócios, mediante uso de uma notação simples, cada qual abordando a modelagem sob diferentes aspectos.

Neste estudo utiliza-se o IDEF0, que trata da representação hierárquica do processo decomposta em atividades ou funções, estabelecendo a quantidade de níveis necessária para obter-se o grau de detalhamento desejado. A técnica IDEF0 está especificada e justificada nos procedimentos metodológicos. No IDEFO original, o processamento de cada atividade dá-se através do modelo Input, Control, Output, Mechanism (ICOM) - ou entrada, controle, saída, mecanismo, em português.

Al-Hakim (2008) modifica a técnica com três elementos adicionais; orientação, restrição e feedback. Esses elementos formam a "informação de governança", que gerencia, regula e controla a implementação das atividades no processo. Cada caixa representa uma atividade com os quatro elementos do modelo ICOM: entrada, controle, saída e mecanismo. A definição de controle para IDEFO é semelhante à definição de orientação, ou seja, o controle são as políticas, procedimentos e regras que controlam a atividade.

Figura 4 - Elementos de informação de uma atividade - uma modificação do IDEFO

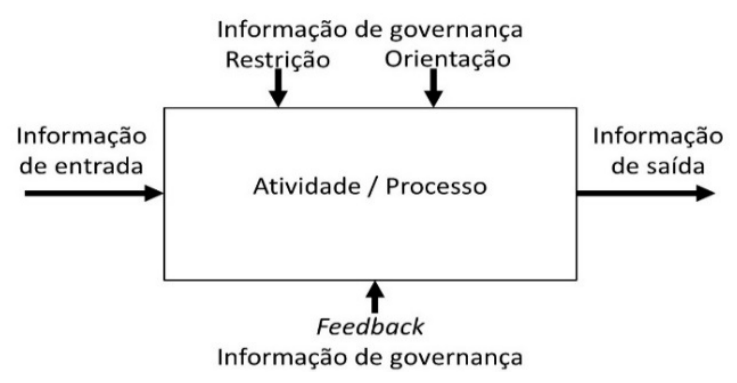

Fonte: Al-Hakim (2008, p. 66, tradução nossa).

Com essa modificação, Al-Hakim (2008) justifica como o IDEF0 pode ser usado efetivamente para mapear fluxos de atividade.

\subsection{A matriz Atividade/Conceito}

A partir deste fluxo de informações usando o IDEF0, é possível identificar as interdependências entre os elementos de informação (Figura 5). 
Figura 5 - Interdependências no fluxo de informação (numeradas de 1 a 5)

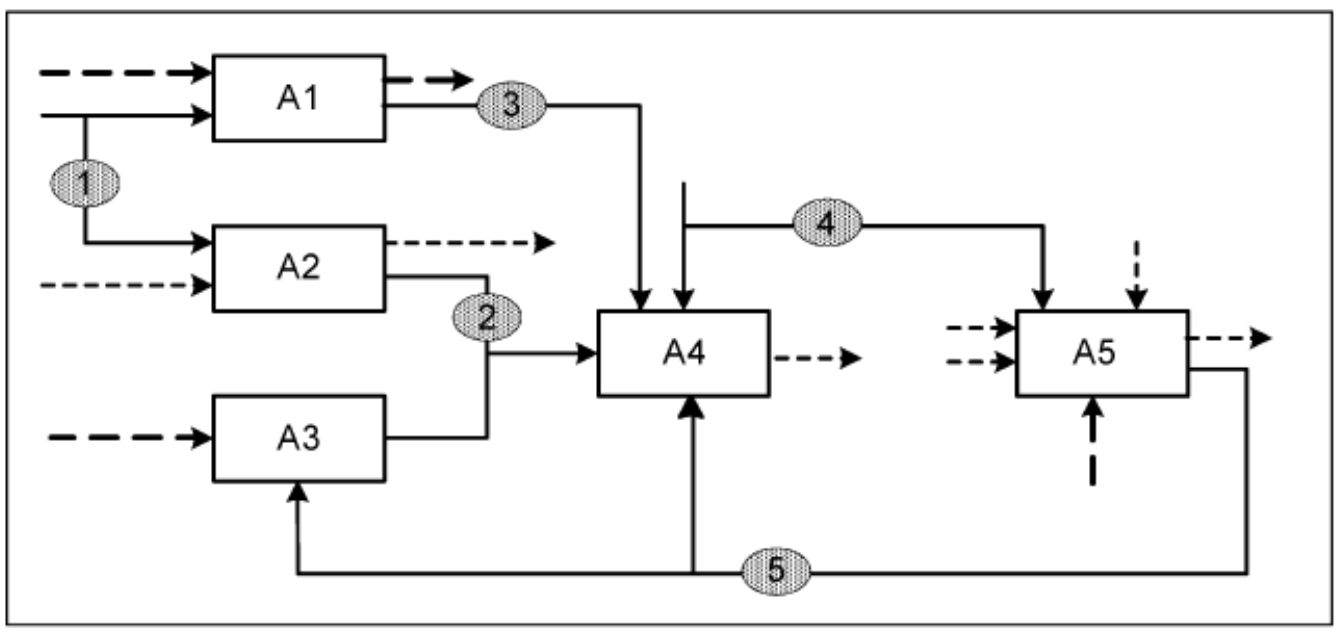

Fonte: Adaptado de Al-Hakim (2008, p. 66).

As relações de dependência podem ser: 1) Dependência de entrada: conforme mostra a Figura 6, as atividades A1 e A2 recebem a informação 1; 2) Dependência de saída: é 0 caso das atividades A2 e A3, que geram uma entrada para A4; 3) Dependência de restrição: é o caso da atividade A1 em relação à atividade A4; 4) Dependência de orientação: as atividades A4 e A5 compartilham da diretriz numerada na figura como 4; 5) Dependência de feedback. quando a saída de uma atividade subsequente forma feedback para uma atividade, essas duas atividades formam uma dependência de feedback, conforme as atividades $\mathrm{A} 5 \mathrm{e} \mathrm{A} 3$.

É possível que duas ou mais atividades compartilhem o mesmo feedback. Essas dependências podem ser mapeadas usando formatos de gráficos ou matrizes.

A matriz indicada por Al-Hakim (2008) para trabalhar o IDEF0 é a matriz Atividade/Conceito $(A / C)$, que identifica as dependências entre os elementos do fluxo de informações. 0 autor afirma que, quando um elemento na matriz, visível através da coluna, possui mais de uma entrada, o elemento forma a interdependência. Percebemos que, na Matriz Atividade/Conceito ( $A / C)$, os símbolos são os mesmos do IDEF0, sem sua adaptação, ou seja, transcrevem-se nas linhas todas as atividades, e, nas colunas, todos os elementos contidos no fluxo de informação, usando o IDEF0 (Figura 5). São empregados os símbolos "I", que se refere à entrada; "0", que se refere à saída. 0 símbolo "C" referese às informações de controle, que nessa matriz serão representadas pelas informações de governança de orientação e de restrição, sendo necessário o suporte da Figura 5 para identificar essas informaç̧ões. Por fim, o "M" refere-se ao feedback, como mostra a Figura 6. 
Figura 6 - Matriz Atividade/Conceito (A/C) do IDEF0
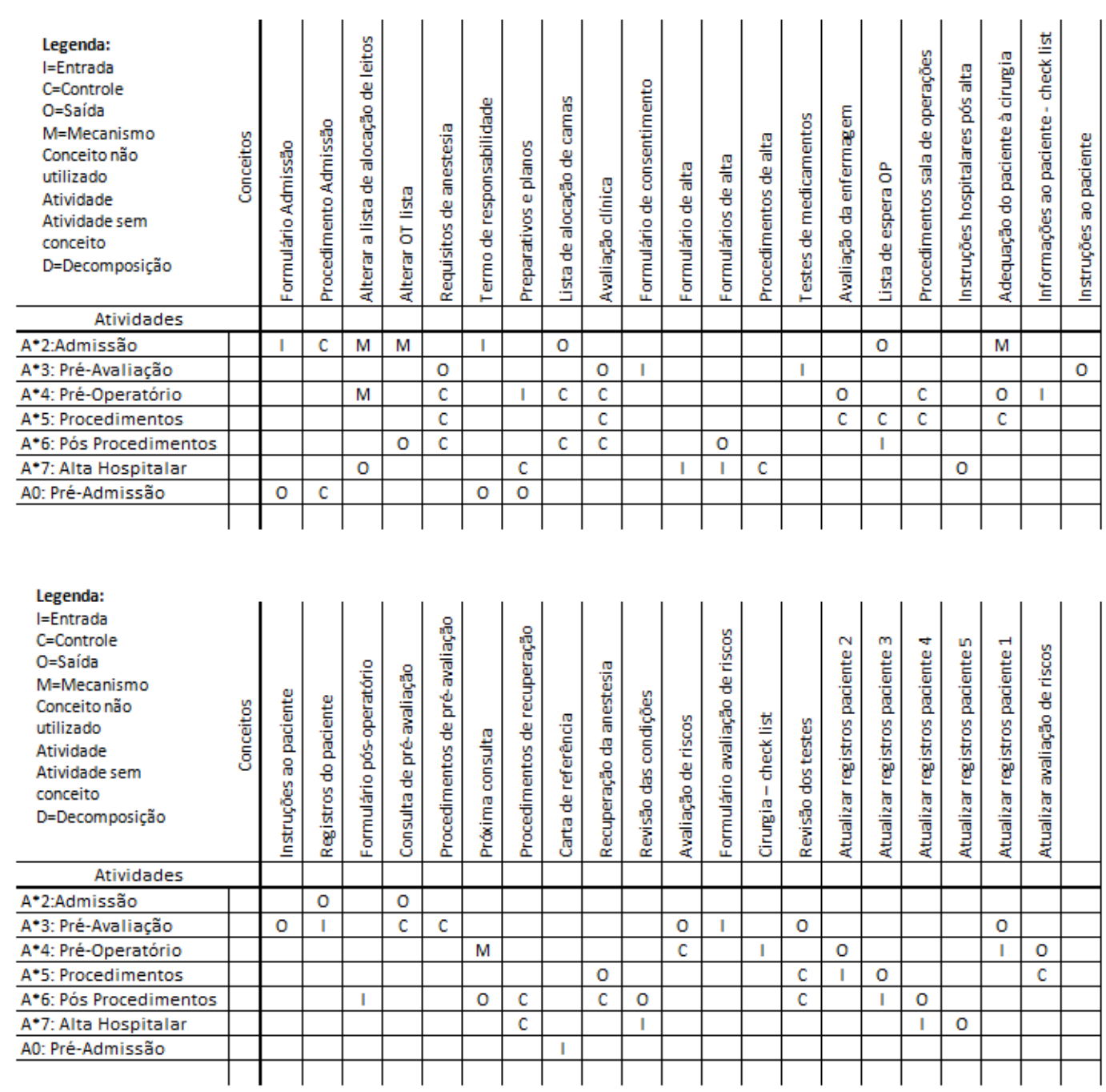

Fonte: al-hakim (2008, p. 70 tradução nossa).

A partir das Figuras 5 e 6, 0 autor exemplifica a dependência de restrição, quando apresenta que 0 elemento "requisitos de anestesia" possui uma entrada com o símbolo "0", e três entradas com o "C". 0 que mostra que este elemento é uma saída da atividade de pré-avaliação e controla as atividades: pré-operatórias, procedimento cirúrgico e pós-operatório. Além disso, é uma restrição, e as quatro atividades formam uma dependência de restrição. Quando duas entradas forem marcadas com "C" e não houver nenhum "O" na coluna que representa esse elemento, significa que se trata de uma orientação. Se na mesma coluna houver marcações "C" e "O", esse elemento será uma restrição. 


\subsection{A matriz de governança}

A matriz Atividade/Conceito (A/C) citada por Al-Hakim (2008) pode ser muito utilizada para tabular as interdependências derivadas da modificação do DSM, através da chamada Matriz de Governança. Assim como no DSM, a Matriz de Governança utiliza linhas e colunas que representam as atividades do processo na ordem em que elas são executadas. No entanto, a Matriz de Governança utiliza apenas os elementos de orientação e elementos de feedback, não considerando os elementos de entrada e saída. Cada linha representa uma atividade e as células da matriz que correspondem às colunas representam as atividades que fornecem orientação ou feedback. A célula marcada abaixo da diagonal da matriz indica informações de uma atividade anterior que gera uma restrição para a subsequente, os elementos representados podem causar atrasos. Já a célula marcada na metade superior indica um feedback onde informações de uma atividade posterior podem agir como feedback de uma anterior, e esses elementos podem causar interrupção, como mostrado na Figura 7.

Figura 7 - Matriz de Governança

\begin{tabular}{|c|c|c|c|c|c|c|c|c|}
\hline Orientação & Atividade & Pré-admissão & Admissão & Pré-Avaliação & Pré-Operatório & Procedimentos & Pós Procedimentos & Alta Hospitalar \\
\hline $\begin{array}{l}\text { Procedimento } \\
\text { Admissão }\end{array}$ & Pré-admissão & & & & & & & \\
\hline $\begin{array}{l}\text { Procedimento } \\
\text { Admissão }\end{array}$ & Admissão & & & & Adequação do Paciente à Cirurgia & & Emendas OT lista & \begin{tabular}{|l|} 
Alterar \\
Alocação de \\
Leitos \\
\end{tabular} \\
\hline $\begin{array}{l}\text { Procedimento } \\
\text { de Avaliação }\end{array}$ & Pré-Avaliação & & \begin{tabular}{|l|} 
Consulta de \\
Pré- \\
Avaliação \\
\end{tabular} & & Próxima Consulta & & & \\
\hline $\begin{array}{l}\text { Procedimento } \\
\text { OT }\end{array}$ & Pré-Operatório & & \begin{tabular}{|l|} 
Lista de \\
alocação de \\
leitos Lista \\
de espera OT
\end{tabular} & $\begin{array}{l}\text { Avaliação de Risco } \\
\text { Requerimento Anestésico } \\
\text { Avaliação Clínica }\end{array}$ & & & & \begin{tabular}{|l|} 
Alterar \\
Alocação de \\
Leitos \\
\end{tabular} \\
\hline $\begin{array}{l}\text { Procedimento } \\
\text { OT } \\
\end{array}$ & Procedimentos & & $\begin{array}{l}\text { lista de } \\
\text { espera OT }\end{array}$ & \begin{tabular}{|l|} 
Teste de Rerisão \\
Requerimento Anestésico \\
Avaliação Clínica
\end{tabular} & $\begin{array}{l}\text { Anestesia Rerersa } \\
\text { Atualização de Araliação de Risco } \\
\text { Adequação do Paciente à Cirurgia }\end{array}$ & & & \\
\hline $\begin{array}{l}\begin{array}{l}\text { Procedimento } \\
\text { de operação }\end{array} \\
\end{array}$ & Pós Procedimentos & & \begin{tabular}{|l|} 
Lista de \\
alocação de \\
leitos \\
\end{tabular} & \begin{tabular}{|l|} 
Teste de Rerisão \\
Requerimento Anestésico \\
Avaliação Clínica
\end{tabular} & & & & \\
\hline $\begin{array}{l}\begin{array}{l}\text { Procedimento } \\
\text { de operação }\end{array} \\
\end{array}$ & Alta Hospitalar & \begin{tabular}{|l|} 
Planejamento \\
de Alta \\
Hospitalar \\
\end{tabular} & & & & & & \\
\hline
\end{tabular}

Fonte: Adaptado de Al-Hakim (2008, p. 71).

\section{APOSENTADORIA NO SERVIÇO PÚBLICO FEDERAL}

Até o final dos anos 1980, o sistema de proteção social brasileiro combinou um modelo de seguro social na área previdenciária, que incluía atenção à saúde, com um modelo assistencial para a população que não exigia vínculos empregatícios formais (FLEURY; ALVES, 2004). A partir da Constituição de 1988 a Seguridade Social passou a constituir o tripé das políticas sociais de saúde, 
assistência social e previdência social, tendo como base a garantia dos direitos fundamentais aos indivíduos.

No presente estudo, que trata do processo de aposentadoria dos servidores públicos civis da União, mais especificamente do cargo de Professor de Magistério Superior, a ênfase recai sobre um dos eixos da seguridade social: a Previdência Social.

No âmbito federal, a Lei n. 8.112 de 1991 instituiu o Regime Jurídico Único (RJU) de trabalho estatutário dos servidores da União, revogando o antigo Estatuto dos Funcionários Públicos Civis da União disposto na Lei n. 1.711, de 28 de outubro de 1952 (BRASIL, 1991). No entanto, somente em 1998, o governo federal estabeleceu as normas básicas obrigatórias para o Regime Próprio de Previdência Social (RPPS), como a aprovação da Emenda Constitucional n. 20, com a edição da Lei n. 9.717, de 27.11.1998 (BRASIL, 1998a). A partir desta lei os servidores titulares de cargos efetivos são afastados do Regime Geral de Previdência Social (RGPS), permanecendo nele os servidores temporários e ocupantes de cargos comissionados.

Assim, a Emenda Constitucional n² 20/98 optou pela manutenção dos regimes públicos de repartição, diferenciando o sistema previdenciário brasileiro em quatro regimes que agrupam em dois grandes segmentos: a previdência social, de caráter público (que abarca o RGPS, o RPPS e o Regime dos Militares), e a previdência complementar, de caráter privado (BRASIL, 1998b):

Os docentes das universidades são servidores da União, regidos pela Lei 8.112/91, que disciplina, dentre outras questões, a aposentadoria do servidor público. Atualmente, os servidores públicos possuem regras e parâmetros de idade e tempo de contribuição para adquirir direito à aposentadoria.

Outras modificações nos regimes da previdência, e em especial atingindo o servidor público, como a Emenda Constitucional n. 41, de 31 de dezembro de 2003 (BRASIL, 2003), aprofundaram as mudanças feitas pela Emenda Constitucional n. 20/98. Para os servidores públicos federais, que incluem os professores, houve a extinção do direito à aposentadoria com base na totalidade da última remuneração e ter seus proventos revistos na mesma proporção. Também propõe regras de transição em seu art. $2^{0}$.

A Emenda Constitucional 41/2003 ainda prevê que o professor que, até o dia 16/12/1998, tenha ingressado, regularmente, em cargo efetivo de magistério e que opte por aposentar-se por esta regra de transição terá o tempo de serviço exercido até a referida data acrescido de 17\% (dezessete por cento) para homens e de $20 \%$ (vinte por cento) para mulheres, desde que se aposente, exclusivamente, com tempo de efetivo exercício nas funções de magistério (BRASIL, 2003). 
Como parte do processo de reforma da previdência do servidor público, foi criada a Emenda Constitucional n. 47/2005, em 6 de julho de 2005 (BRASIL, 2005), com uma nova regra de aposentadoria para os servidores públicos em atividade que ingressaram no serviço público até 16.12.98, que, em seu art. $3^{0}$, prevê uma compensação entre a idade mínima para aposentadoria (55 anos para mulheres e 60 anos para homens) e o tempo de contribuição (30 anos para mulheres e 35 anos para homens). Por meio dessa regra, por exemplo, um homem com 36 anos de contribuição pode se aposentar aos 59 anos de idade.

A Ementa Constitucional n. 70/2012 (BRASIL, 2012) estabeleceu direito a proventos com paridade e de acordo com a última remuneração (integrais ou proporcionais), caso venha a se aposentar por invalidez. A mais recente proposta de reforma até abril de 2020, ano de fechamento desta pesquisa, é a PEC 06/2019, que, além das alterações na idade e no tempo de serviço definidas, também alterará na alíquota de contribuição para o imposto de renda.

As mudanças nas aposentadorias dos professores, por si sós, já justificam a otimização do fluxo de informações, que, como já discutida na literatura sobre a temática, pode ser alcançada por meio da reorganização das sequências de atividades, minimização das trocas de informações e gerenciamento das iterações.

\section{PROCEDIMENTOS METODOLÓGICOS}

Esta pesquisa tem o percurso descritivo e documental, com técnicas de coletas de dados baseadas em documentos e legislação, conforme descrito a seguir.

Quanto aos seus objetivos, esta é uma pesquisa descritiva, uma vez que "os estudos de natureza descritiva se propõem a investigar o 'que é', ou seja, a descobrir as características de um fenômeno como tal" (RICHARDSON et al., 1985, p. 27). 0 estudo descritivo representa um nível de análise que permite identificar as características dos fenômenos, possibilitando, também, a ordenação e a classificação destes.

No que se refere aos procedimentos técnicos, o estudo é caracterizado também como pesquisa documental, uma vez que uma extensa base legal fundamenta as ações do processo de aposentadoria. Normas, leis, portarias e decretos se caracterizam como documentos relevantes neste estudo. Entre as normas presentes na maioria dos contextos das universidades, cujo objeto é processo de aposentadoria dos servidores públicos federais, estão aquelas que governam a informação. Fazem parte de uma 
pesquisa documental também os elementos pertencentes a sistemas informatizados, como é o caso do Sistema de Administração de Pessoas (SIAPE).

Esta pesquisa fez uma adaptação do IDEFO de modo que ele possa ser usado para mapear elementos de fluxo de informações e identificar as interdependências entre eles. Também depende parcialmente dos princípios da DSM para construir uma matriz que possa identificar vários elementos de informações de governança. A “informação de governança” gerencia, regula e controla a implementação das atividades (Al-HAKIM, 2008). A identificação de elementos de informações de governança e suas interdependências é o primeiro passo para melhorar a variação do processo em termos de redução de atrasos e interrupções.

Neste trabalho foram previstas entrevistas com quatro servidores, escolhidos devido aos cargos e funções que ocupam, além de serem os principais atuantes no processo de aposentadoria, gerando ou fornecendo informações para compor o documento. Para identificar as várias etapas do processo de trabalho e do fluxo de informações foram realizadas entrevistas, com objetivo de englobar as concepções e experiências dos entrevistados, entender o significado que eles davam às ocorrências e eventos que circundam o tema, utilizando suas próprias palavras (LAKATOS; MARCONI, 2017). A técnica de pesquisa qualitativa utilizada foi a entrevista semiestruturada, pois, conforme Lakatos e Marconi (2017), o entrevistador tem autonomia para elaborar o roteiro em qualquer direção que considere pertinente, com questões previamente elaboradas.

Finalmente, foi criada uma matriz de governança do processo de aposentadoria dos professores da universidade. 0 resultado da modificação do DSM é uma matriz, conhecida como "matriz de governança" (AI-HAKIM, 2008), que fornece um formulário tabular (em formato de tabela) que identifica os elementos de informação que possam causar atrasos ou interrupções.

\section{APRESENTAÇÃO DE RESULTADOS}

Uma entrevista com a Diretora do Departamento de Administração de Pessoas foi realizada para obter as informações iniciais necessárias para entender como se dividem os subprocessos e atividades do processo de aposentadoria. Com todo o fluxo do processo apresentado, além das informações contidas no estudo de Neiva (2020), foi possível identificar que a aposentadoria voluntária era a mais requisitada, implicando em uma alteração na dinâmica do setor envolvido. Com isso, duas entrevistas foram efetuadas com a Seção de Aposentadoria e Pensão para verificar as 
informações e atividades do processo de aposentadoria voluntária. 0 primeiro encontro possibilitou revisar as informações de mapeamento das coletas nas reuniões anteriores pelas gestões, momento em que algumas atividades tiveram uma análise mais aprofundada, pois tratava-se de comandos e telas de sistemas.

Já, no segundo, o fluxo do processo foi construído e as informações e documentos necessários para cada fase foram identificados. A partir desses dados, concluiu-se que o processo de aposentadoria pode ser descrito em três etapas: Formação do processo de aposentadoria; Tramitação do processo de aposentadoria; e Implementação do processo de aposentadoria no SIAPE e no sistema do TCU. Após essa análise, houve a necessidade de entender como ocorriam as atividades desenvolvidas pelo setor de Assessoria de Legislação de Pessoas, pois esse foi 0 setor indicado por todos os entrevistados. Uma entrevista foi marcada com o chefe da assessoria, que detalhou todas as informações utilizadas e fornecidas, tanto para o servidor solicitante, quanto para os outros setores. A assessoria também valida todos os documentos e tramitações e emite um parecer positivo ou negativo a respeito do caso, além de dirimir dúvidas do servidor a respeito dos fundamentos legais que compõem a sua aposentadoria.

0 fluxo das atividades realizadas em todo o processo de aposentadoria foi identificado. Todas as informações utilizadas foram elencadas, fossem elas provenientes de documentos ou sistemas ou fornecidas pelos setores. 0 processo tramita por sete setores da instituição: 1) 0 protocolo, onde 0 processo é iniciado; 2) a seção de Aposentadoria e Pensão (SAP), que é setor responsável pela coleta de dados e concretização da aposentadoria no sistema; 3) a Comissão Permanente de Sindicância e Inquérito (CPSI), encarregada de sinalizar se o servidor responde a algum processo administrativo ou disciplinar que impossibilite a aposentadoria até 0 julgamento do caso; 4) a Assessoria de Legislação de Pessoas (ALP), que verifica se o processo e os atos estão obedecendo às determinações legais; 5) a Reitoria, administração superior autorizada para validar 0 ato; 6) a Secretaria Geral da PROGEPE, setor que emite e publica a portaria de aposentadoria no Diário Oficial da União, 0 que oficializa 0 ato; e 7) a Seção de Arquivamento e Registro Funcional (SARF), que registra 0 ato na pasta funcional do servidor e arquiva o processo no sistema de arquivamento digital. Foram identificadas, em cada etapa, as atividades desenvolvidas e registradas no processo, totalizando 28 (vinte e oito), apresentadas no Quadro 1. 
Quadro 1 - Relação de atividades do processo de aposentadoria voluntária

\begin{tabular}{|c|l|c|l|}
\hline Nr. & \multicolumn{1}{|c|}{ Descrição } & Nr. & \multicolumn{1}{|c|}{ Descrição } \\
\hline 1 & Requerer aposentadoria & 15 & Emitir portaria \\
\hline 2 & $\begin{array}{l}\text { Validar documentação pela chefia } \\
\text { imediata }\end{array}$ & 16 & Publicar portaria no DOU \\
\hline 3 & Verificar documentação anexada (SAP) & 17 & Assinar o ato de concessão \\
\hline 4 & Inserir telas do sistema SIAPE & 18 & Entregar a portaria de aposentadoria \\
\hline 5 & Coletar documentos da pasta funcional & 19 & Entregar a declaração do PIS/PASEP \\
\hline 6 & Inserir mapa de tempo de serviço & 20 & Atualizar endereço no SIAPE \\
\hline 7 & $\begin{array}{l}\text { Incluir afastamentos listados no } \\
\text { SIAPEnet }\end{array}$ & 21 & Realizar o acerto financeiro \\
\hline 8 & Verificar se servidor responde à PAD & 22 & Emitir acerto financeiro \\
\hline 9 & Encaminhar processo para ALP com & & Incluir aposentadoria no SIAPE \\
\hline 10 & Convocar servidor para esclarecimentos & 24 & Fazer cálculo de aposentadoria \\
\hline 11 & Verificar uso de licença-prêmio & 25 & $\begin{array}{l}\text { Lançar a concessão na folha de } \\
\text { pagamento }\end{array}$ \\
\hline 12 & $\begin{array}{l}\text { Verificar detalhes do fundamento } \\
\text { escolhido }\end{array}$ & 26 & Emitir mapa de tempo de serviço \\
\hline 13 & Escolher nomenclatura legal & 27 & $\begin{array}{l}\text { Registrar aposentadoria no e-Pessoal. } \\
\text { (TCU) }\end{array}$ \\
\hline 14 & Autorizar a emissão da portaria & 28 & Arquivar o processo \\
\hline
\end{tabular}

Fonte: Adaptado de Lira (2020, p. 62-63).

As atividades podem ser divididas conforme as etapas do processo. Na primeira etapa, formação do processo de aposentadoria, as atividades registradas são a 1 e a 2. Já, na segunda tramitação do processo de aposentadoria, as atividades foram elencadas de 3 a 19; e a terceira, implementação do processo de aposentadoria no SIAPE, é formada pelas atividades 20 a 28. A instrumentalização e os documentos utilizados e concebidos foram detalhados em entrevistas. Durante o levantamento de informações no SIAPE, foram identificados três documentos institucionais como muito importantes no processo: o formulário da PROGEPE, a convocação do servidor pela ALP e a declaração do PIS/PASEP. Com o fluxo das informações detalhado, foram aplicadas as ferramentas propostas pelo estudo, a DSM e a IDFE0.

A primeira técnica, a DSM, foi utilizada para identificar o fluxo de informações do processo de aposentadoria, com o intuito de responder ao questionamento dado por Eppinger (2001), isto é, quais informações cada atividade deste processo necessita de outras equipes para a sua realização? Com a lista das atividades pronta, a ferramenta DSM pôde ser desenhada e tal questionamento foi respondido. A Figura 8 mostra a aplicação da ferramenta DSM no processo de aposentadoria voluntária. 
Figura 8 - DSM do processo de aposentadoria

\begin{tabular}{|c|c|c|c|c|c|c|c|c|c|c|c|c|c|c|c|c|c|c|c|c|c|c|c|c|c|}
\hline Atividades & & \begin{tabular}{l|l}
1 & 2 \\
\end{tabular} & 2 & 3 & 4 & 5 & 6 & 788 & 8 & \begin{tabular}{l|l|l|}
9 & 10 \\
\end{tabular} & 11 & 12 & 13 1 & \begin{tabular}{l|l|l}
14 & 1
\end{tabular} & \begin{tabular}{l|l}
15 & 1 \\
15 & 0
\end{tabular} & $16 \mid 17$ & \begin{tabular}{l|l}
7 & 18
\end{tabular} & 819 & 20 & \begin{tabular}{l|l}
21 & 2 \\
\end{tabular} & 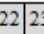 & \begin{tabular}{l|l}
3 & 24 \\
\end{tabular} & 25 & 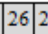 & \begin{tabular}{l|l|}
27 & 28 \\
\end{tabular} \\
\hline Requerer aposentadoria & 1 & & & & & & & & & & & & & & & & & & & & & & & & \\
\hline Validar documentação pela chefia imediata & 2 & $\mathrm{x}$ & & & & & & & & & & & & & & & & & & & & & & & \\
\hline Verificar documentação anexada (SA.P) & \begin{tabular}{l|l}
3 \\
\end{tabular} & 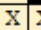 & $\mathrm{x}$ & & & & & & & & & & & & & & & & & & & & & & \\
\hline Inserir telas do sistema SIAPE & 4 & & & $\mathrm{x}$ & & & & & & & & & & & & & & & & & & & & & \\
\hline Coletar documentos da pasta funcional & 5 & & & $\mathrm{x}$ & & & & & & & & & & & & & & & & & & & & & \\
\hline Inserir mapa de tempo de serviço & 6 & & & $\mathrm{x}$ & & $\mathrm{x}$ & & & & & & & & & & & & & & & & & & & \\
\hline Incluir afastamento listados no SIAPEnet & 7 & & & $\mathrm{x}$ & & & & & & & & & & & & & & & & & & & & & \\
\hline Verificar se servidor responde à PAD & 8 & & & $\mathrm{x}$ & & & & & & & & 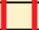 & & & & & & & & & & & & & \\
\hline Encaminhar processo para ALP com declaração & 9 & & & & & & & & $\mathrm{x}$ & & & & & & & & & & & & & & & & \\
\hline Convocar servidor para esclarecimentos & 10 & & & $\mathrm{x}$ & & & & & $\mathrm{x}$ & $\mathrm{x}$ & & & & & & & & & & & & & & & \\
\hline Verificar uso de licença prêmio & 11 & & & $\mathrm{x}$ & & & & & t & $\mathrm{x}$ & & a & & & & & & & & & & & & & \\
\hline Verificar detalhes do fundamento escolhido & 12 & & & 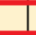 & & 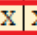 & $\mathrm{x}$ & 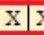 & $\mathrm{x}$ & $\mathrm{x}$ & $\mathrm{x}$ & 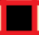 & & & & & & & & & & & & & \\
\hline Escolher nomenclatura legal & 13 & & & & & & & & & & & $\bar{x}$ & & & & & & & & & & & & & \\
\hline Autorizar a emissão da portaria & 14 & & & & & & & & & $\mathrm{x}$ & & 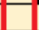 & $\mathrm{x}$ & & & & & & & & & & & & \\
\hline Emitir portaria & 15 & & & & & & & & & & & 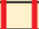 & & $\mathrm{x}$ & & & & & & & & & & & \\
\hline Publicar portaria no DOU & 16 & & & & & & & & & & & 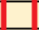 & & & $\mathrm{x}$ & & & & & & & & & & \\
\hline Assinar o ato de concessão & 17 & & & & & & & & & & & & & & & $\mathrm{x}$ & & & & & & & & & \\
\hline Entregar da portaria de aposentadoria & 18 & & & & & & & & & & & 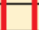 & & \begin{tabular}{l|l}
$\mathrm{x}$ & $\mathrm{x}$ \\
$\mathrm{n}$
\end{tabular} & 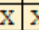 & $\mathrm{x} \mathrm{x}$ & & & & & & & & & \\
\hline Entregar a declaração do PIS/PASEP & 19 & & & & & & & & & & & & & & & & $\mathrm{x}$ & & & & & & & & \\
\hline Atualizar endereço no SIAPE & 20 & $\mathrm{x}$ & & $\mathrm{x}$ & & & & & & & & & & & & & & & & & & & & & \\
\hline Realiza o acerto financeiro & 21 & & & & & & & & & & & 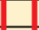 & & & 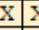 & $\mathrm{x} / \mathrm{x}$ & & & & & & & & & \\
\hline Emitir acerto financeiro & 22 & & & & & & & & & & & . & & & & & & & & $\mathrm{x}$ & & & & & \\
\hline Inclvir aposentadoria no SLAPE & 23 & & & $\mathrm{x}$ & & & & & & & $\mathrm{x}$ & $\mathrm{x}$ & $\mathrm{x}$ & & \begin{tabular}{l|ll}
$\mathrm{x}$ & $\mathrm{x}$ \\
\end{tabular} & \begin{tabular}{l|l}
$\mathrm{x}$ & $\mathrm{x}$ \\
$\mathrm{n}$
\end{tabular} & & & & & $\mathrm{x}$ & & & & \\
\hline Fazer cálculo de aposentadoria & 24 & & & & & & $\mathrm{x}$ & & & & $\mathrm{x}$ & $\mathrm{x}$ & $\mathrm{x}$ & & & $\mathrm{x}$ & & & & & $\mathrm{x}$ & $\mathrm{Q}$ & & & \\
\hline Lançar a concessão na folha de pagamento & 25 & & & & & & & & & & & & & & & & & & & & $\mathrm{x} \mid \mathrm{x}$ & $\mathrm{x} x \mathrm{x}$ & & & \\
\hline Emitir mapa de tempo de serviço & 26 & & & $\mathrm{x}$ & & & $\mathrm{x}$ & & & & & & & & & $\mathrm{x}$ & & & & & & & & & \\
\hline Registrar aposentadoria no e-Pessoal. (TCU) & 27 & & & & & & & & & & & & & & & $\mathrm{x}$ & & & & & & & & $\mathrm{x}$ & \\
\hline Arquivar o processo & 28 & & & & & & & & & & & . & & & & & & & & & & & & & $\mathrm{x}$ \\
\hline
\end{tabular}

Fonte: Lira (2020, p. 64).

Assim, com 0 uso da ferramenta de Eppinger (2001) para este processo, é possível ver que a atividade da linha 12 mostra que ela precisa de informações das atividades 5, 6, 7, 8, 10 e 11 . Por outro lado, a atividade da coluna 12 fornece informações para as atividades 13, 23, e 24. Em relação às trocas de informações de feedforward e feedback, propostas na ferramenta de Eppinger (2001), o processo de aposentadoria voluntária dos docentes encontra-se em conformidade em relação ao fluxo das informações, pois não apresenta necessidade de reformulação, nem mesmo a antecipação de retrabalho, já que nenhuma atividade realizada posteriormente é pré-requisito de uma atividade anterior. Também é possível observar que o processo não possui atividades paralelas, pois todas as atividades dependem da anterior para prosseguir. De acordo com relatos obtidos em entrevistas à SAP, o processo não apresenta iterações, ou seja, atividades simultâneas e repetidas, visto que passou por reorganizações das sequências das atividades, identificando as atividades sequenciais. Além disso, houve a redução no número de trocas de informações, mediante inclusão de conhecimento ou experiência da outra atividade em um componente da equipe, mediante treinamentos para repassar as informações ou remover o servidor de setor, a fim de otimizar os fluxos de informações.

Outra ferramenta proposta para apresentar os resultados desta pesquisa é o IDEF0, utilizada conforme as adaptações que Al-Hakim (2008) realizou para acomodar os elementos de fluxos de informação associados à atividade e para identificar as interdependências entre os elementos de informação. Para criar 
o IDEF0 das atividades listadas no Quadro 1, em consonância com a proposta de Al-Hakim (2008), foi realizado um agrupamento dessas atividades em um nível macro, pois entendemos que a representação das entradas, saídas, restrições, orientação e feedback para 28 funções tornaria o desenho muito extenso e detalhado. Assim, optou-se por realizar um agrupamento que resultou em nove atividades, sendo, para tal, considerado principalmente, mas não exclusivamente, o local onde a atividade é realizada (Quadro 2).

Quadro 2 - Agrupamento das atividades em nível macro

\begin{tabular}{|c|c|c|c|}
\hline $\begin{array}{l}\text { Nr. } \\
\text { Macro }\end{array}$ & Descrição Macro & $\begin{array}{c}\mathrm{Nr} . \\
\text { Detalhe }\end{array}$ & Descrição \\
\hline 1 & \multirow{3}{*}{$\begin{array}{c}\text { Requerer } \\
\text { aposentadoria } \\
\text { Validar } \\
\text { documentação pela } \\
\text { chefia imediata }\end{array}$} & & \\
\hline 2 & & & \\
\hline \multirow{5}{*}{3} & & 3.1 & Verificar documentação anexada (SAP) \\
\hline & \multirow{4}{*}{$\begin{array}{l}\text { Coletar dados } \\
\text { funcionais do } \\
\text { servidor }\end{array}$} & 3.2 & Inserir telas do sistema SIAPE \\
\hline & & 3.3 & Coletar documentos da pasta funcional \\
\hline & & 3.4 & Inserir mapa de tempo de serviço \\
\hline & & 3.5 & Incluir afastamentos listados no Siapenet \\
\hline \multirow{3}{*}{4} & \multirow{3}{*}{$\begin{array}{l}\text { Checar possíveis } \\
\text { problemas de PAD } \\
\text { ou sindicância }\end{array}$} & 4.1 & Verificar se servidor responde à PAD \\
\hline & & 4.2 & Encaminhar processo para ALP com declaração \\
\hline & & 5.1 & Convocar servidor para esclarecimentos \\
\hline \multirow[t]{3}{*}{5} & \multirow{3}{*}{$\begin{array}{l}\text { Verificar requisitos } \\
\text { para aposentadoria }\end{array}$} & 5.2 & Verificar uso de licença prêmio \\
\hline & & 5.3 & Verificar detalhes do fundamento escolhido \\
\hline & & 5.4 & Escolher nomenclatura legal \\
\hline \multirow{4}{*}{6} & \multirow{4}{*}{$\begin{array}{l}\text { Executar } \\
\text { procedimentos } \\
\text { sobre portaria na } \\
\text { Reitoria }\end{array}$} & 6.1 & Autorizar a emissão da portaria \\
\hline & & 6.2 & Emitir portaria \\
\hline & & 6.3 & Publicar portaria no DOU \\
\hline & & 6.4 & Assinar 0 ato de concessão \\
\hline \multirow[b]{2}{*}{7} & \multirow{2}{*}{$\begin{array}{c}\text { Informar } \\
\text { aposentadoria ao } \\
\text { servidor } \\
\end{array}$} & 7.1 & Entregar a portaria de aposentadoria \\
\hline & & 7.2 & Entregar a declaração do PIS/PASEP \\
\hline \multirow{7}{*}{8} & \multirow{7}{*}{$\begin{array}{l}\text { Atualizar sistemas } \\
\text { após portaria }\end{array}$} & 8.1 & Atualizar endereço no SIAPE \\
\hline & & 8.2 & Realizar 0 acerto financeiro \\
\hline & & 8.3 & Emitir acerto financeiro \\
\hline & & 8.4 & Incluir aposentadoria no SIAPE \\
\hline & & 8.5 & Fazer cálculo de aposentadoria \\
\hline & & 8.6 & Lançar a concessão na folha de pagamento \\
\hline & & 8.7 & Emitir mapa de tempo de serviço \\
\hline \multirow{2}{*}{9} & \multirow{2}{*}{$\begin{array}{l}\text { Finalizar processo } \\
\text { de aposentadoria }\end{array}$} & 9.1 & Registrar aposentadoria no e-Pessoal. (TCU) \\
\hline & & 9.2 & Arquivar o processo \\
\hline
\end{tabular}

Fonte: Lira (2020, p. 65-66). 
Antes da criação do IDFE0, essa hierarquização das atividades foi apresentada em uma ilustração, pois ela representa visualmente melhor o que foi definido no Quadro 2. Após essa identificação, construiu-se o Quadro 3, que traz as nove atividades (nível macro) do processo de aposentadoria, com suas entradas, saídas, orientações, restrições e feedback, último passo antes da construção da IDEF0.

Considera-se 0 Quadro 3 uma contribuição desta pesquisa como uma ferramenta que auxilia os gestores a definir com mais clareza o que mostra a informação nas atividades, visto que ele não integra os estudos de Al-Hakim $(2005,2007,2008)$, pois o autor parte diretamente para a construção do diagrama IDEF0. A criação do referido quadro para chegar ao desenho do diagrama pode ser um importante passo para gestores que não dispõem ou não querem utilizar ferramentas gráficas, dado 0 trabalho de construção, para representar o fluxo informacional. 
MODELAGEM DO FLUXO DE INFORMAÇ̃̃ES DO PROCESSO DE APONSENTADORIA:

aplicação em uma universiidade pública federal brasileira

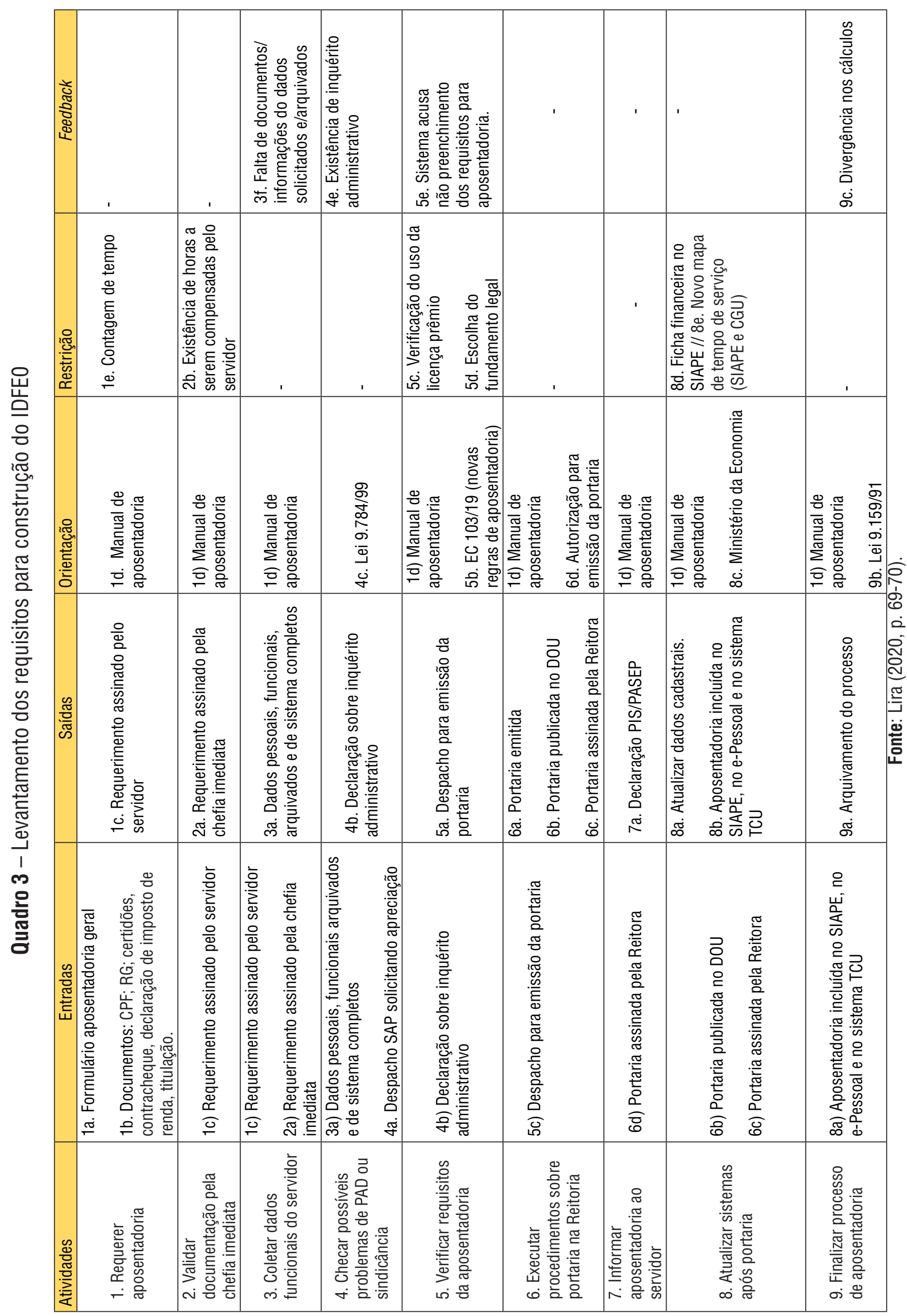




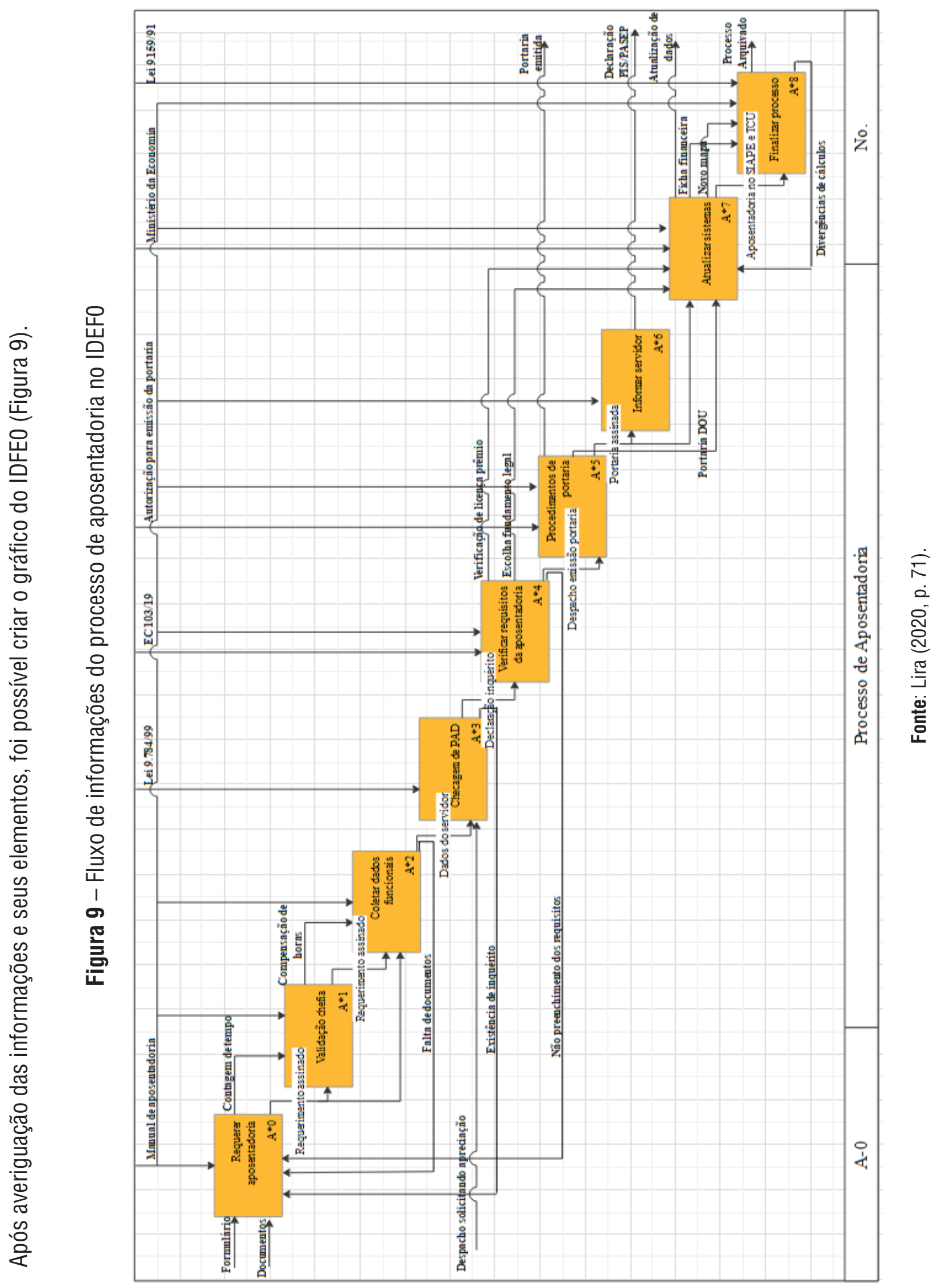


Após a criação do gráfico IDEF0, percebeu-se a facilidade de visualizar os elementos de informação. As leis, manuais ou procedimentos governam cada etapa do processo, como o manual de aposentadoria; a Lei 9.784/99; Lei 9.159/91, Emenda Constitucional 103/19, dentre outros. Possíveis atrasos e interrupções podem existir caso algum requisito não seja cumprido, por exemplo, a falta de algum documento exigido na atividade 2 paralisará o processo até que o servidor sane a pendência. Os elementos de uma determinada atividade dependem de elementos de outras atividades e 0 relacionamento entre elas forma as interdependências, que são: entrada, saída, restrição, orientação e feedback. Obteve-se o reconhecimento das dependências do processo de aposentadoria, mostrado na Figura 10.

Figura 10 - Dependências do processo de aposentadoria

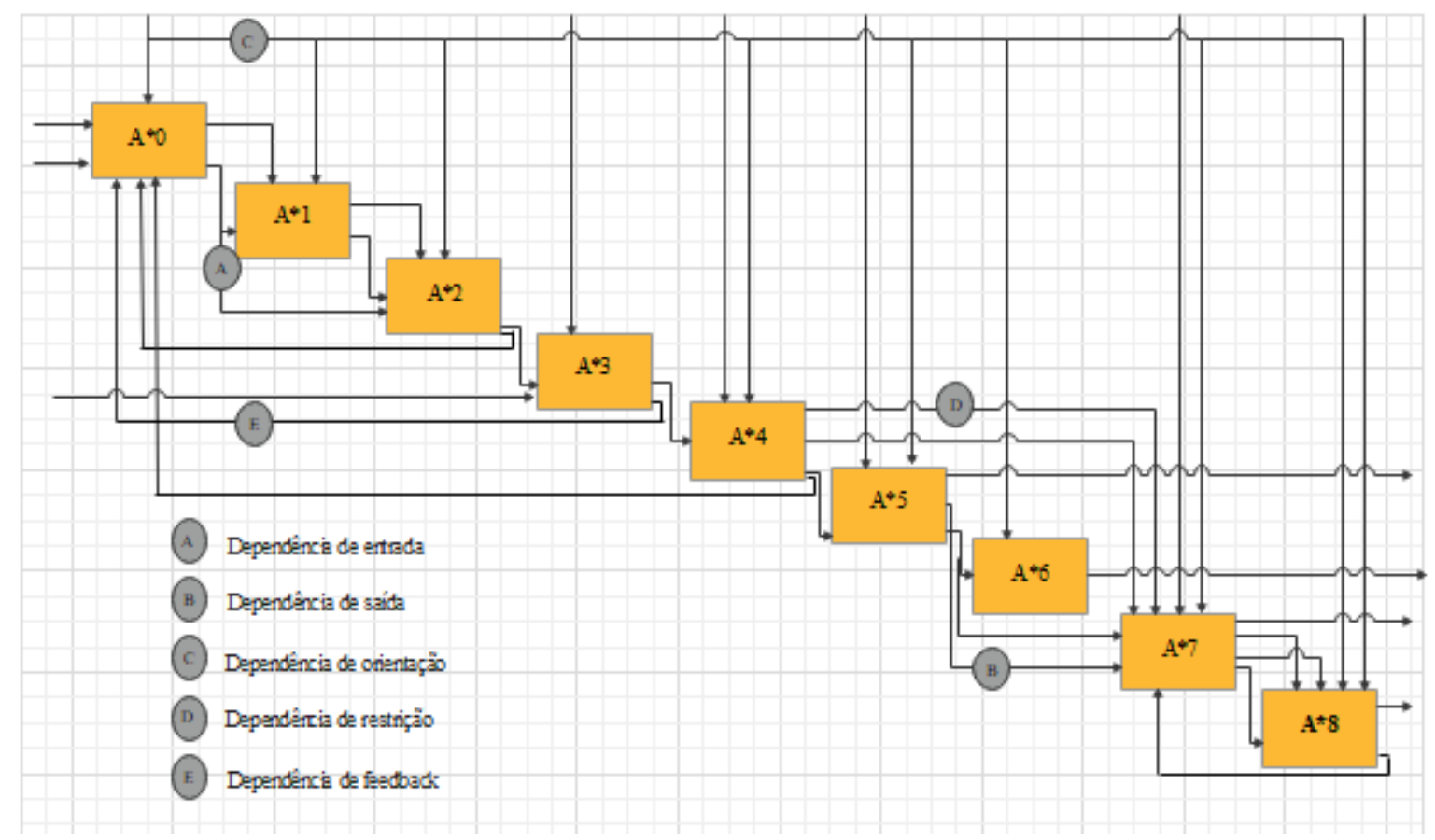

Fonte: Lira (2020, p.72).

Outra ferramenta que mostra a interdependência dos elementos é a Matriz Atividade/Conceito $(\mathrm{A} / \mathrm{C})$, apresentada na Figura 11. De acordo com a pesquisa, o processo de aposentadoria de docentes da universidade, analisado pela matriz A/C, apresenta apenas dependência de orientação, visto que a coluna que representa o elemento "manual de aposentadoria" aponta oito entradas com a legenda "C" em oito atividades.

Para que possa existir dependência de restrição é preciso que haja, numa mesma coluna de um elemento, mais de três entradas de uma atividade, sendo uma com a legenda "0" e pelo menos duas 
com a legenda "C". 0 elemento que apresenta a legenda "0" é uma saída da atividade vinculada a ele, enquanto controla as atividades que possuem a legenda "C" associada a ela, e isto significa dizer que o elemento com legenda "0" é uma restrição. E para ter dependência de feedback é necessário que haja, numa mesma coluna, um elemento com mais de três entradas de uma atividade, sendo uma com a legenda "O" e pelo menos duas com a legenda "M". 0 elemento que apresenta a legenda "O" é saída da atividade vinculada a ele, enquanto forma feedback com as atividades que possuem a legenda "M" associada a elas.

Após elencar as dependências da matriz de Atividade/Conceito ( $\mathrm{A} / \mathrm{C})$, ela foi utilizada para, enfim, alcançar o objetivo geral deste trabalho, que é construir a Matriz de Governança do fluxo de informações do processo de aposentadoria dos professores de uma universidade pública federal (Figura 12). Essa matriz é uma versão adaptada do DSM e elenca apenas controle e feedback, pois não leva em consideração as entradas e as saídas. Como mostra a Figura 12, as células marcadas abaixo da diagonal representam restrição das atividades listadas na sua linha e são atividades que podem causar atrasos e retrabalhos. As informações identificadas foram: contagem de tempo, declaração de que 0 servidor não possui horas a serem compensadas, escolha do fundamento legal, verificação do uso da licença-prêmio, ficha financeira, novo mapa de tempo. 


\begin{tabular}{|c|c|c|c|c|c|c|c|c|c|c|}
\hline 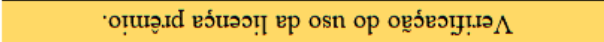 & & & & & 0 & & & 0 & & \\
\hline 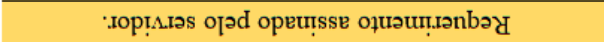 & & ロ & - & & & & & & & 0 \\
\hline 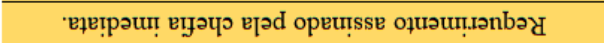 & & 0 & ๑ & & & & & & & \\
\hline оредт̣nb.re ossəoo. $\mathrm{I}_{\mathrm{d}}$ & & & & & & & & & 0 & \\
\hline 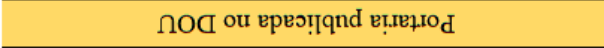 & & & & & & 0 & & ロ & & \\
\hline 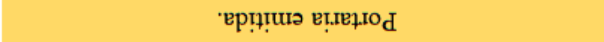 & & & & & & 0 & & & & \\
\hline 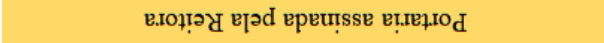 & & & & & & 0 & 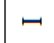 & - & & \\
\hline odurə⿻ әр вdeи олоN & & & & & & & & 0 & u & \\
\hline 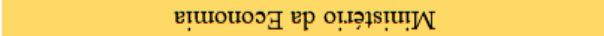 & & & & & & & & 0 & & \\
\hline 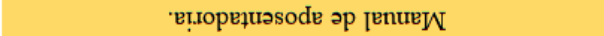 & & 0 & 0 & & 0 & $u$ & u & 0 & u & 0 \\
\hline $66 / t 8 L^{\circ} 6$ !อ Т & & & & u & & & & & & \\
\hline I6/6Sโ 6 !’ Т & & & & & & & & & u & \\
\hline 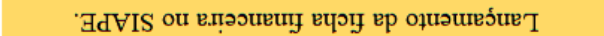 & & & & & & & & & & \\
\hline 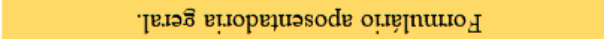 & & & & & & & & & & - \\
\hline 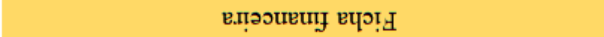 & & & & & & & & 0 & u & \\
\hline 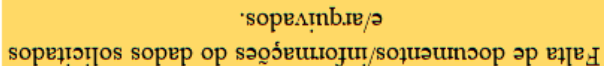 & & & 0 & & & & & & & $\Sigma$ \\
\hline 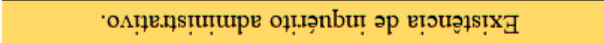 & & & & 0 & & & & & & $\Sigma$ \\
\hline 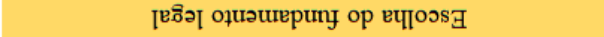 & & & & & 0 & & & 0 & & \\
\hline $6 \mathrm{I} / \varepsilon 0 \mathrm{I} \mathrm{\supset H}$ & & & & & 0 & & & & & \\
\hline sołtuaunood & & & & & & & & & & $\square$ \\
\hline 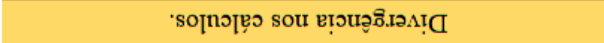 & & & & & & & & $\Sigma$ & 0 & \\
\hline 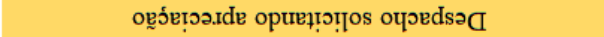 & & & & $\varpi$ & & & & & & \\
\hline 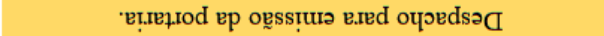 & & & & & 0 & ๑ & & & & \\
\hline 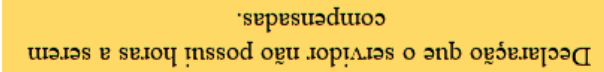 & & 0 & U & & & & & & & \\
\hline 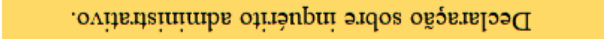 & & & & 0 & - & & & & & \\
\hline 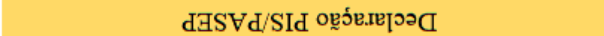 & & & & & & & 0 & & & \\
\hline 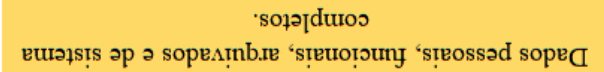 & & & 0 & - & & & & & & \\
\hline 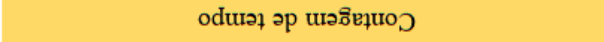 & & u & & & & & & & & 0 \\
\hline 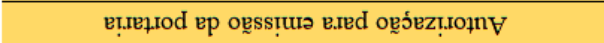 & & & & & & 0 & & & & \\
\hline 'șe.qsepes sopep .rez!̣eny & & & & & & & & 0 & & \\
\hline 'ossaso.rd op oquaurestnb.r. & & & & & & & & & & \\
\hline 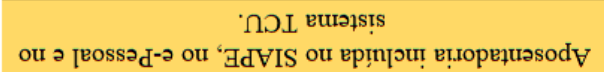 & & & & & & & & 0 & 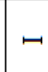 & \\
\hline 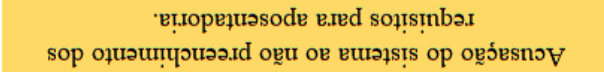 & & & & & 0 & & & & & $\Sigma$ \\
\hline оџ!әวшоว & & & & & & & & & & \\
\hline 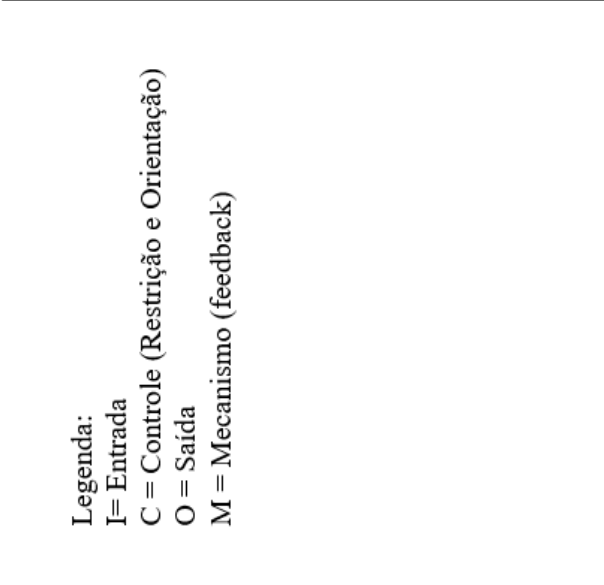 & 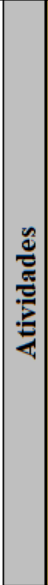 & 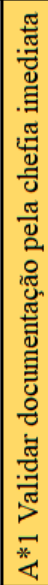 & 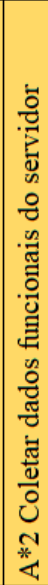 & 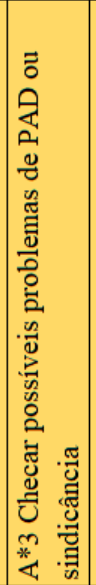 & 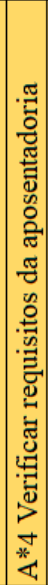 & 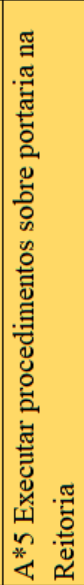 & 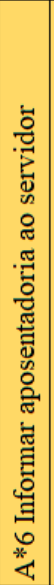 & 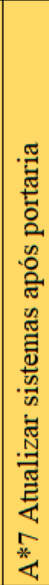 & 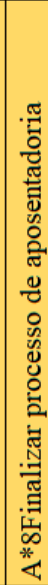 & 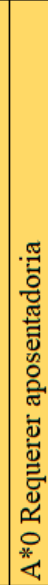 \\
\hline
\end{tabular}


A contagem de tempo pode causar atraso se for percebido que o servidor não possui tempo suficiente para aposentar-se, acarretando a paralização do processo até que tal requisito seja alcançado. A declaração de que o servidor não possui horas a serem compensadas pode também gerar atrasos ao processo, caso a chefia decida que o docente precisa cumprir a carga horária em débito. A escolha do fundamento legal pode gerar atraso se o servidor acreditar que tem tempo bastante para se aposentar por integralidade, mas, no momento em que receber os esclarecimentos, identifica que tem contagem de tempo apenas para a aposentadoria proporcional, necessitando ficar mais alguns anos em serviço para que possa se aposentar com valor integral. No caso da verificação do uso da licença-prêmio, ela pode gerar atraso caso o servidor não se recorde de que gozou a Licença-Prêmio por Assiduidade e, por isso, não poder realizar a contagem em dobro do período, aspecto necessário para a complementação do requisito tempo mínimo. A ficha financeira pode atrasar o processo, se as rubricas de rendimento não forem lançadas no mês seguinte ao da aposentadoria, conforme orienta o manual de aposentadoria. Se isso ocorrer, é necessário solicitar liberação junto ao Ministério da Economia, o que pode ser prejudicial para o servidor. E, por fim, entra também, neste conjunto de atividades que podem gerar atraso, o novo mapa de tempo, que deve utilizar para sua execução o registro da data anterior à aposentadoria do servidor; se a contagem não for realizada desta forma, haverá alteração nos valores financeiros, sendo preciso seu reajuste.

A falta de documentos ou informações dos dados solicitados ou arquivados pode provocar interrupção no processo, que ficará parado até que o docente resolva a pendência. A existência de inquérito administrativo interrompe o fluxo do processo, que somente voltará a tramitar em duas situações possíveis: a) quando o inquérito for julgado ou b) passado o prazo de 140 dias, de acordo com a Lei 9.784/99 (BRASIL, 1999). Quando o sistema acusa não preenchimento dos requisitos para aposentadoria, gera um feedback do processo até que os requisitos não preenchidos sejam reparados. E, por último, a divergência nos cálculos causará um retorno do processo se for observada a falta de algum dos valores que compõem a ficha financeira, como férias, afastamentos, licenças.

Diante do exposto, verificou-se que as principais informações que geram atrasos e interrupções são: documentos pessoais; documentos que comprovem a vida funcional do servidor antes de pertencer ao quadro da universidade; informações que evidenciem os reconhecimentos de títulos; o conhecimentos da existência de afastamentos, licenças ou faltas que necessitem ser compensados. 
MODELAGEM DO FLUXO DE INFORMAÇ̃̃ES DO PROCESSO DE APONSENTADORIA:

aplicação em uma univerśidade pública federal brasileira

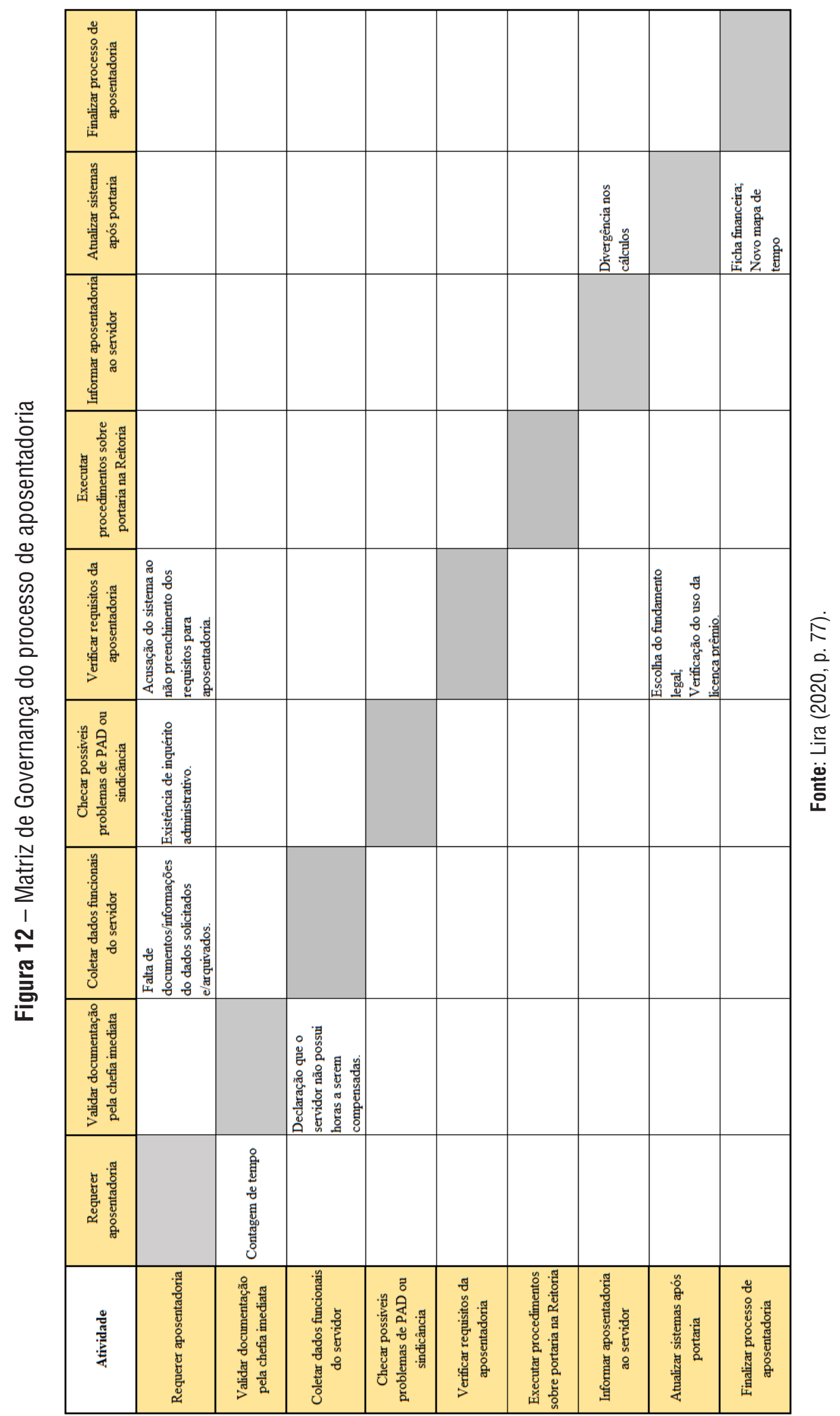




\section{CONSIDERAÇÕES FINAIS}

Esta pesquisa utilizou as ferramentas DSM e IDEF0 como recurso para propor a matriz de governança do fluxo de informações do processo de aposentadoria dos professores de uma universidade pública federal, na perspectiva de oferecer aos envolvidos uma percepção mais aprofundada do quanto as informações necessárias são importantes no processo.

Por meio da ferramenta DSM foi possível identificar que o fluxo de informações do processo de aposentadoria da universidade apresenta alinhamento coerente com as 28 atividades identificadas no processo, em resposta ao primeiro objetivo específico proposto. A instituição desenvolveu, antes da referida pesquisa, mecanismos de melhoria na descrição das atividades e nas informações necessárias para que cada uma delas pudesse ser executada. Foram realizadas pela universidade, para facilitar e acelerar o fluxo de informações entre as atividades, ações como transferir conhecimentos-chave entre as equipes, adicionando a cada equipe alguém com experiência na outra atividade; alterar a ordem de execução das atividades, realocando-as de forma a evitar iterações; 0 acréscimo de uma ou duas atividades extras para intervir entre as atividades existentes no grupo, bem como dividir as atividades agrupadas em conjuntos menores, alterando as especificações da atividade.

A aplicação da técnica IDEFO possibilitou a visualização rápida dos elementos que governam, restringem ou implementam uma atividade no processo, por meio da identificação dos elementos das informações de governança e suas dependências, em resposta ao segundo objetivo específico. Como resultado da análise das interdependências, comprovou-se que o processo de aposentadoria possui duas dependências de entrada, oito de orientação, seis de restrição e quatro de feedback. No entanto, na matriz A/C, a pesquisa obteve apenas uma dependência de orientação, não possuindo nenhuma outra, de acordo com seus requisitos, comprovando o terceiro objetivo específico da pesquisa. Confirmando a importância do objetivo geral deste trabalho, quando a matriz de governança foi construída, as atividades que possuíam atrasos e interrupções foram identificadas, a partir dos requisitos exigidos pela matriz ao usar o suporte da matriz $\mathrm{A} / \mathrm{C}$ e da ferramenta DSM. Observou-se que as informações que geram esses atrasos e interrupções, geralmente, são: documentos pessoais; documentos que comprovem a vida funcional do servidor antes de pertencer ao quadro da universidade; informações que evidenciem os reconhecimentos de títulos; o conhecimentos da existência de afastamentos, licenças ou faltas que necessitem ser compensados. 
A falta de informações sobre as leis que regem o processo de aposentadoria, por parte do servidor, pode ocasionar algum tipo de retrabalho. Uma situação típica ocorre quando o servidor se depara com a existência de um inquérito administrativo que o impede de se aposentar. No entanto, não somente 0 docente precisa ter atenção às informações que complementam o processo, para evitar os atrasos, como também os servidores que trabalham na geração ou na utilização das informações nos sistemas. A falta de conhecimento ou de atenção ao inserir as informações no sistema pode acarretar retrabalho com as correções de erros identificados. É necessário observar a data de lançamento da aposentadoria no sistema SIAPE, para não haver discordância na ficha financeira, já que essa só deve ser lançada na folha seguinte do mês da concessão da aposentadoria. Se for lançada no mesmo mês da publicação no DOU, as rubricas de rendimento podem não ser computadas, e é preciso solicitar liberação do sistema ao Ministério da Economia para fazer o reajuste. Outra atenção que o servidor da SAP deve ter é consultar se todas as rubricas constam na folha de pagamento do mês seguinte, pois, caso falte alguma, ela deve ser inserida manualmente.

Diante do exposto, os resultados encontrados a partir da utilização das ferramentas DSM e IDEF0 mostram que existem algumas informações que os docentes precisam averiguar antes de dar entrada no processo de aposentadoria, já que a maioria dos atrasos e interrupções é devida à falta de conhecimento quanto aos requisitos ou documentos da vida profissional do docente que se precisará ao longo do processo, conforme mencionado nas entrevistas. 0 trabalho realizado com as duas ferramentas auxilia tanto o servidor a identificar quais os passos que precisam ser dados antes de requerer a aposentadoria, como a administração superior a verificar com clareza cada função, quais seus requisitos, como adaptar o processo de acordo com as necessidades de modificação das atividades, onde estão os potenciais atrasos e retrabalhos e as melhores condições do sistema.

Recomendamos, a partir desta pesquisa, que a administração disponibilize uma cartilha com todas as orientações necessárias e requisitos exigidos em todas as etapas do processo de aposentadoria, e implemente um sistema de consultas on-line, com os dados e documentos funcionais exigidos, para que o servidor se informe sobre a existência de todas as informações, para não haver atrasos ou interrupção. De forma conclusiva, pode-se assegurar que as informações apontadas no presente estudo constituem um importante instrumento de fluxo de informações em todas as atividades que compõem o processo de aposentadoria, que, neste caso, foram identificadas em um total de 28. As ferramentas de gestão aqui utilizadas constituem importante instrumento de gestão para visualização do fluxo informacional do processo de aposentadoria, como o diagrama IDEF0, a matriz atividade/conceito, 
a matriz de governança (produto final do trabalho) e o quadro criado para representar textualmente as entradas, saídas, orientações, restrições e feedback, Esta pesquisa alerta os servidores sobre a atenção que deve ser dada não somente às atividades, mas, principalmente, ao fluxo de informações que transitam entre elas.

\section{REFERÊNCIAS}

AL-HAKIM, L. Web-based hospital information system for managing operating theatre waiting list. International Journal of Healthcare Technology and Management, v. 7, n. 3-4, p. 266-282, 2005.

AL-HAKIM, L. IDEF3-based framework for web-based hospital information system. In: AL-HAKIM, L (org.). Web mobile-based applications for healthcare management. IRM Press, Hershey: PA, 2007. p. 376-401.

AL-HAKIM, L.Modelling information flow for surgery management process. International Journal of Information Quality, v. 2, n. 1, p. 60-74, 2008.

BRASIL. Presidência da República. Casa Civil. Lei nº 8.212, de 24 de julho de 1991. [1991].

Disponível em: http://www.planalto.gov.br/ccivil_03/leis/l8212cons.htm. Acesso em: 12 jun. 2020.

BRASIL. Presidência da República. Casa Civil. Lei nº 9.717, de 27 de novembro de 1998. [1998a]. Disponível em: http://www.planalto.gov.br/ccivil_03/_ato2011-2014/2012/lei/l12618.htm. Acesso em:12 jun. 2020.

BRASIL. Presidência da República. Casa Civil. Emenda Constitucional nº 20 de 1998. [1998b]. Disponível em: http://www.planalto.gov.br/ccivil_03/constituicao/emendas/emc/emc20.htm. Acesso em: 12 jun. 2020.

BRASIL. Presidência da República. Casa Civil. Lei nº 9.784 de 29 de janeiro de 1999. [1999]. Acesso em: http://www.planalto.gov.br/ccivil_03/leis//9784.htm. Acesso em: 12 jun. 2020.

BRASIL. Presidência da República. Casa Civil. Emenda Constitucional n . 41 de 2003. [2003]. Disponível em: http://www.planalto.gov.br/ccivil_03/constituicao/Emendas/Emc/emc41.htm. Acesso em: 12 jun. 2020.

BRASIL. Presidência da República. Casa Civil. Emenda Constitucional n . 47 de 2005. [2005]. Disponível em: http://www.planalto.gov.br/ccivil_03/constituicao/emendas/emc/emc47.htm. Acesso em: 12 jun. 2020.

BRASIL. Presidência da República. Casa Civil. Emenda constitucional nr. 70 de 29 de março de 2012. [2012]. Disponível em: http://www.planalto.gov.br/ccivil_03/constituicao/emendas/emc/emc70. htm. Acesso em: 12 jun. 2020.

BRASIL. Ministério do Planejamento, Desenvolvimento e Gestão. Manual de Procedimentos: Aposentadoria. Ministério do Planejamento, Desenvolvimento e Gestão, Secretaria de Gestão de Pessoas. 1. ed. Brasília: MP, 2017. 103 p. 
BRASIL. Presidência da República. Casa Civil. PEC nº6 de 2019. [2019]. Disponível em: https:// www.camara.leg.br/proposicoesWeb/fichadetramitacao?idProposicao=2192459. Acesso em: 12 jun. 2020.

D'ÁVILA, R. Modelagem de processos organizacionais utilizando a matriz de estrutura baseada em atividades. In: ENCONTRO NACIONAL DE ENGENHARIA DE PRODUÇÃO, 26., 2006, Fortaleza. Anais[...]. Fortaleza: UFCE, 2006.

EPPINGER, S. D. Innovation at the speed of information. Harvard Business Review, v. 79, p. 3-11, Jan./Feb. 2001.

FLEURY, Sonia; ALVES, Rosangela. Reforma previdenciária no Brasil em três momentos. Revista de Administração Pública, Rio de Janeiro, v. 38, n. 6, p. 979-1022, nov./dez. 2004.

LAKATOS, E. M; MARCONI, M. A. Metodologia científica. 7. ed. São Paulo: Atlas, 2017.

LILLRANK, P. The quality of information. International. Journal of Quality and Reliability Management, v. 20, p. 691-703, 2003.

LIRA, Luciana Pessoa Guedes. 0 fluxo de informações do processo de aposentadoria de uma Universidade pública federal. 2020. 102 f. Dissertação (Mestrado em Gestão Pública). Universidade Federal de Pernambuco, CCSA, 2020.

NEIVA, R. M. B. M. Gestão da informação aplicada aos processos de aposentadoria dos professores da UFRPE: uma análise frente às emendas constitucionais à Constituição de 1988. 2020. Dissertação (Mestrado em Gestão Pública) - Universidade Federal de Pernambuco, CCSA, 2020.

RICHARDSON, R. J. et al. Pesquisa social. Métodos e técnicas. São Paulo: Atlas, 1985. 